\title{
Improving Clustering Analysis for Credit Card Accounts Classification
}

\author{
Yi Peng ${ }^{1}$, Gang Kou ${ }^{1}$, Yong $\mathrm{Shi}^{1,2,3, *}$, and Zhengxin $\mathrm{Chen}^{1}$ \\ ${ }^{1}$ College of Information Science \& Technology, University of Nebraska at Omaha, \\ Omaha, NE 68182, USA \\ \{ypeng, gkou, yshi, zchen\} @mail.unomaha.edu \\ ${ }^{2}$ Graduate School of Chinese Academy of Sciences, Beijing 100039, China \\ ${ }^{3}$ The corresponding author
}

\begin{abstract}
In credit card portfolio management, predicting the cardholders' behavior is a key to reduce the charge off risk of credit card issuers. The most commonly used methods in predicting credit card defaulters are credit scoring models. Most of these credit scoring models use supervised classification methods. Although these methods have made considerable progress in bankruptcy prediction, they are unsuitable for data records without predefined class labels. Therefore, it is worthwhile to investigate the applicability of unsupervised learning methods in credit card accounts classification. The objectives of this paper are: (1) to explore an unsupervised learning method: cluster analysis, for credit card accounts classification, (2) to improve clustering classification results using ensemble and supervised learning methods. In particular, a general purpose clustering toolkit, CLUTO, from university of Minnesota, was used to classify a real-life credit card dataset and two supervised classification methods, decision tree and multiple-criteria linear programming (MCLP), were used to improve the clustering results. The classification results indicate that clustering can be used to either as a stand-alone classification method or as a preprocess step for supervised classification methods.
\end{abstract}

Keywords: Credit Card Accounts Classification, Clustering analysis, CLUTO, unsupervised learning method.

\section{Introduction}

One of the major tasks in credit card portfolio management is to reliably predict credit cardholders' behaviors. This task has two impacts in credit management: (1) identify potential bankrupt accounts and (2) develop appropriate policies for different categories of credit card accounts. To appreciate the importance of bankrupt accounts prediction, some statistics are helpful: There are about 1.2 billion credit cards in circulation in US. The total credit card holders declared bankruptcy in 2003 are 1,625,208 which are almost twice as many as the number of 812,898 in 1993 [4]. The total credit

* This research has been partially supported by a grant from National Natural Science Foundation of China (\#70472074). 
card debt at the end of the first quarter 2002 is about $\$ 660$ billion [1]. Bankrupt accounts caused creditors millions of dollars lost each year. In response, credit card lenders have made great effort to improve traditional statistical methods and recognized that more sophisticated analytical tools are needed in this area. Development of appropriate policies for various groups of credit card accounts also has a great impact on credit card issuers' profits. From the creditor's standpoint, the desirable policies should help to keep the profitable customers and minimize the defaults.

Under this strong business motivation, various techniques have been developed and applied to credit card portfolio management. The survey conducted by Rosenberg and Gleit [5] about quantitative methods in credit management provides a comprehensive review of major analytical techniques. According to Rosenberg and Gleit, discriminant analysis is the most popular quantitative tool in credit analysis at that time. In addition, integer programming, decision trees, expert systems, neural networks, and dynamic models are also available. Although these methods have made considerable progress in bankruptcy prediction, most of them are supervised learning methods. That is, they require previous knowledge about credit card accounts to make prediction. Supervised learning methods have both advantage and disadvantage. Supervised learning can normally achieve high prediction accuracy if the historical data and the data need to be analyzed have similar characteristics. The disadvantage is that supervised learning methods can not be used if there are no data records with known class labels. Therefore, it is worthwhile to investigate the usefulness of unsupervised learning in credit card accounts classification. Compare with supervised learning methods, unsupervised classification methods require no previous class labels of records. Rather, they classify data records based on their underlying structures or characteristics.

The objectives of this paper are: (1) to explore an unsupervised learning method: cluster analysis, for credit card accounts classification, (2) to improve clustering classification results using ensemble and supervised learning methods. In other words, this paper is trying to investigate the applicability of clustering both as a stand-alone classification method and as a preprocess step for supervised classification methods. In particular, a general purpose clustering toolkit, CLUTO, from university of Minnesota, was used to classify a real-life credit card dataset. Due to the fact that unsupervised classification methods normally have lower prediction accuracies than supervised method, two supervised classification method, decision tree and multiplecriteria linear programming (MCLP) [6], were used to improve the clustering results based on the clustering analysis results.

This paper is organized as follows: section 2 briefly introduces cluster analysis and CLUTO, section 3 outlines the features of credit card dataset used in the paper, section 4 illustrates how the proposed process can be applied to credit card accounts classification and reports the results, and section 5 summarizes the paper.

\section{Cluster Analysis and CLUTO}

Cluster analysis refers to group data records into clusters based on some criterion functions. Cluster can be defined as a collection of data records that are similar to one another within the same cluster and dissimilar to the records in other clusters. 
Clustering is categorized as an unsupervised classification method because it does not require predefined classes. Instead, clustering algorithms automatically group data records by recognizing their underlying structures and characteristics. Clustering can be applied to different data types, including interval-scaled variables, binary variables, nominal variables, ordinal variables, and ratio-scaled variables, and various application areas, including pattern recognition, image processing, life science, and economic science [3].

According to different criteria, clustering methods can be classified into different categories. Han and Kamber [3] divided clustering methods into five approaches: partitioning, hierarchical, density-based, grid-based, and model-based. Partitioning methods construct a partition of the original dataset into $k$ clusters that optimizes the partitioning criterion and $k$ is predefined. Hierarchical methods can be either agglomerative or divisive. Agglomerative algorithms assign each data object to its own cluster and then repeatedly merging clusters until a stopping criterion is met [7]. Divisive algorithms treat all data records as one cluster and then repeatedly splitting clusters until a stopping criterion is met. Density-based algorithms cluster data records according to their density. Grid-based algorithms use multi-resolution data structure and represent datasets in n-dimensional feature space. Model-based algorithms try to optimize the fit between the data and some mathematical models.

Various commercial and free softwares have been designed to implement different clustering algorithms. CLUTO is a general purpose clustering toolkit developed by Department of Computer Science \& Engineering, University of Minnesota [2]. CLUTO was chose in this research for three major reasons. First, CLUTO provides multiple classes of clustering algorithms and uses multiple similarity/distance functions. Second, CLUTO has been successfully used in application areas like information retrieval, customer purchasing transactions, web, GIS, science, and biology (CLUTO 2003). Third, CLUTO is free software.

\section{Credit Card Dataset Description}

The raw data came originally from a major US bank. It contains 6000 records and 102 variables (38 original variables and 64 derived variables) describing cardholders' behaviors. The 6000 credit card records were randomly selected from 25,000 real-life credit card records. The data were collected from June 1995 to December 1995 (seven months) and the cardholders were from twenty-eight States in USA. This dataset has been used as a classic working dataset by credit card issuers for various data analyses to support the bank's business intelligence. Each record has a class label to indicate its' credit status: either Good or Bad. Bad indicates a bankrupt credit card account and Good indicates a good status account. Within the 6000 records, 960 accounts are bankrupt accounts and 5040 are good status accounts. The 38 original variables can be divided into four categories: balance, purchase, payment, cash advance, in addition to related variables. The category variables represent raw data of previous six or seven consecutive months. The related variables include interest charges, date of last payment, times of cash advance, and account open date. The 64 derived variables are 
created from the original 38 variables to reinforce the comprehension of cardholder's behaviors, such as times overlimit in last two years, calculated interest rate, cash as percentage of balance, purchase as percentage to balance, payment as percentage to balance, and purchase as percentage to payment. These variables are not static; rather, they are evolving. New variables which are considered important can be added and variables which are proved to be trivia or irrelative in separating can be removed. Among these variables, 8 variables were selected for clustering computation following expert advices. The 8 variables are: Interest charge Dec. 95, Interest charge Dec. 95 as percent of credit line, Number of months since last payment, Credit line, Number of times delinquency in last two years, Average payment of revolving accounts, Last balance to payment ratio, and Average OBT revolving accounts. Due to the space limit, the selection criteria for classification variables will not be discussed here.

\section{Empirical Studies of Cluster Analysis}

As stated in the introduction, this section described two empirical studies of cluster analysis. The first study applied CLUTO to the credit card dataset to generate a set of classification results. The second study tested whether decision tree and MCLP can improve clustering classification results. Decision tree was chosen for study because it is a well-known supervised classification method. MCLP was chosen because it has been demonstrated superior performance in our previous study [6]. The research procedures for the first and second study were summarized in Method 1 and 2.

\section{Method 1}

Input: The data set $\mathrm{A}=\left\{\mathrm{A}_{1}, \mathrm{~A}_{2} \mathrm{~A}_{3}, \ldots, \mathrm{A}_{6000}\right\}$

Output: The clustering analysis results.

Step 1. Select 8 attributes from $\mathrm{A}_{i}=\left(a_{1}, a_{2}, a_{3}, \ldots, a_{64}\right)$, Generate the 6000 credit card data set.

Step 2. Apply the various clustering and analysis algorithms implemented in CLUTO to do a 2 to 20 way clustering analysis.

Step 3. Choose 3 clustering results according to certain criteria.

Step 4. A majority vote committee of 3 results will generate a final analysis result. The performance measures of the classification will be decided by majorities of the committee. If more than 2 of the committee members give out right classification result, then the clustering analysis $\mathrm{C}_{\mathrm{i}}$ for this observation are successful, otherwise, the analysis is failed.

END

\section{Method 2}

Input: The data set $\mathrm{A}=\left\{\mathrm{A}_{1}, \mathrm{~A}_{2} \mathrm{~A}_{3}, \ldots, \mathrm{A}_{6000}\right\}$, The clustering analysis results from Method 1.

Output: The classification results; The optimal solution from MCLP, $X^{*}=$ $\left(x_{1}{ }^{*}, x_{2}{ }^{*}, x_{3}{ }^{*}, \ldots, x_{8}{ }^{*}\right)$; The Decision Tree from See5.

Step 1. Manually selecting several clusters that have highest separation between Good and Bad accounts to form a training dataset $\mathrm{T}$. 
Step 2. Apply the two-group MCLP model to the training dataset T to compute the compromise solution $X^{*}=\left(x_{1}{ }^{*}, x_{2}{ }^{*}, \ldots, x_{8}{ }^{*}\right)$ as the best weights of all 8 variables with given values of control parameters $\left(b, \alpha^{*}, \beta^{*}\right)$.

Step 3. Apply See5 to the training dataset T to compute the Decision Tree and its classification result.

\section{END}

The results of applying Method 1 and 2 were summarized in Table 1 and 2. The average predictive accuracies for Bad and Good groups using CLUTO are $81.17 \%$ and $66.87 \%$ and the average of Type I and Type II error rate of using CLUTO is $36.26 \%$. Compared with these results, ensemble technique improves the classification accuracies (Bad: 91.25\%, Good: 69.84\%) and reduces the average of Type I and Type II error rates $(32.88 \%)$. Both supervised learning methods, decision tree and MCLP, achieved better classification results for Bad records. MCLP generated better average Type I and Type II error rate (34.69\%).

Table 1. Clustering analysis results by CLUTO

\begin{tabular}{|c|c|c|c|c|c|c|c|}
\hline \multicolumn{7}{|c|}{ Bad } & \multicolumn{2}{c|}{ Good } & Type I \\
\hline & $\begin{array}{c}\text { Correctly } \\
\text { Identi- } \\
\text { fied }\end{array}$ & $\begin{array}{c}\text { Accu- } \\
\text { racy } \\
\text { Type II } \\
\text { Error }\end{array}$ & $\begin{array}{c}\text { Correctly } \\
\text { Identi- } \\
\text { fied }\end{array}$ & $\begin{array}{c}\text { Accu- } \\
\text { racy }\end{array}$ & $\begin{array}{c}\text { AVG of } \\
\text { Type I } \\
\text { and II } \\
\text { Error }\end{array}$ \\
\hline 1 & 874 & $91.04 \%$ & 3002 & $59.56 \%$ & $2.78 \%$ & $69.99 \%$ & $36.39 \%$ \\
\hline 2 & 759 & $79.06 \%$ & 3674 & $72.90 \%$ & $5.19 \%$ & $64.28 \%$ & $34.73 \%$ \\
\hline 3 & 893 & $93.02 \%$ & 2754 & $54.64 \%$ & $2.38 \%$ & $71.91 \%$ & $37.14 \%$ \\
\hline 4 & 784 & $81.67 \%$ & 3595 & $71.33 \%$ & $4.67 \%$ & $64.83 \%$ & $34.75 \%$ \\
\hline 5 & 760 & $79.17 \%$ & 3603 & $71.49 \%$ & $5.26 \%$ & $65.41 \%$ & $35.33 \%$ \\
\hline 6 & 687 & $71.56 \%$ & 3595 & $71.33 \%$ & $7.06 \%$ & $67.78 \%$ & $37.42 \%$ \\
\hline 7 & 856 & $89.17 \%$ & 2871 & $56.96 \%$ & $3.50 \%$ & $71.70 \%$ & $37.60 \%$ \\
\hline 8 & 621 & $64.69 \%$ & 3869 & $76.77 \%$ & $8.06 \%$ & $65.35 \%$ & $36.70 \%$ \\
\hline
\end{tabular}

\section{Conclusions}

Classification of credit cardholders' behavior is an important data mining application in banking industry. Situations in which there are no predefined class labels call for unsupervised classification methods. Based on this observation, this paper investigated two roles of an unsupervised classification method, cluster analysis, using a real-life credit card dataset. Cluster analysis can be used as a stand-alone classification method or as a preprocess step for supervised classification methods. The empirical results of this paper indicated that as a stand-alone classification method, cluster analysis generated lower classification rates than supervised methods. However, when combined with supervised methods, the classification results can be improved considerably. 
Table 2. Classification results via Ensemble analysis, MCLP and See5

\begin{tabular}{|c|c|c|c|c|c|c|c|}
\hline \multicolumn{8}{|c|}{ Clustering Ensemble Analysis } \\
\hline & \multicolumn{2}{|c|}{$\mathrm{Bad}$} & \multicolumn{2}{|c|}{ Good } & \multirow[b]{2}{*}{$\begin{array}{l}\text { Type } \\
\text { I } \\
\text { Error }\end{array}$} & \multirow[b]{2}{*}{$\begin{array}{c}\text { Type II } \\
\text { Error }\end{array}$} & \multirow[b]{2}{*}{$\begin{array}{c}\text { AVG } \\
\text { of } \\
\text { Type I } \\
\text { and II } \\
\text { Error }\end{array}$} \\
\hline & $\begin{array}{l}\text { Cor- } \\
\text { rectly } \\
\text { Identi- } \\
\text { fied }\end{array}$ & $\begin{array}{l}\text { Accu- } \\
\text { racy }\end{array}$ & $\begin{array}{l}\text { Correctly } \\
\text { Identi- } \\
\text { fied }\end{array}$ & $\begin{array}{l}\text { Accu- } \\
\text { racy }\end{array}$ & & & \\
\hline $\begin{array}{l}\text { Over- } \\
\text { all }\end{array}$ & 876 & $91.25 \%$ & 3520 & $69.84 \%$ & $2.33 \%$ & $63.44 \%$ & $32.88 \%$ \\
\hline \multicolumn{8}{|c|}{ Multi-Criteria Linear Programming } \\
\hline & $\mathrm{Bad}$ & & Good & & \multirow[b]{2}{*}{$\begin{array}{l}\text { Type } \\
\text { I } \\
\text { Error }\end{array}$} & \multirow[b]{2}{*}{$\begin{array}{c}\text { Type II } \\
\text { Error }\end{array}$} & \multirow[b]{2}{*}{$\begin{array}{c}\text { AVG } \\
\text { of } \\
\text { Type I } \\
\text { and II } \\
\text { Error }\end{array}$} \\
\hline & $\begin{array}{l}\text { Cor- } \\
\text { rectly } \\
\text { Identi- } \\
\text { fied }\end{array}$ & $\begin{array}{l}\text { Accu- } \\
\text { racy }\end{array}$ & $\begin{array}{l}\text { Correctly } \\
\text { Identi- } \\
\text { fied }\end{array}$ & $\begin{array}{l}\text { Accu- } \\
\text { racy }\end{array}$ & & & \\
\hline $\begin{array}{l}\text { Train- } \\
\text { ing }\end{array}$ & 839 & $100.00 \%$ & 719 & $90.67 \%$ & $0.00 \%$ & $8.11 \%$ & $4.05 \%$ \\
\hline $\begin{array}{l}\text { Over- } \\
\text { all }\end{array}$ & 882 & $91.88 \%$ & 3246 & $64.40 \%$ & $2.35 \%$ & $67.04 \%$ & $34.69 \%$ \\
\hline \multicolumn{8}{|c|}{ Decision Tree } \\
\hline & $\mathrm{Bad}$ & & Good & & \multirow[b]{2}{*}{$\begin{array}{c}\text { Type } \\
\text { I } \\
\text { Error }\end{array}$} & \multirow[b]{2}{*}{$\begin{array}{c}\text { Type II } \\
\text { Error }\end{array}$} & \multirow{2}{*}{$\begin{array}{c}\text { AVG } \\
\text { of } \\
\text { Type I } \\
\text { and II } \\
\text { Error }\end{array}$} \\
\hline & $\begin{array}{l}\text { Cor- } \\
\text { rectly } \\
\text { Identi- } \\
\text { fied }\end{array}$ & $\begin{array}{l}\text { Accu- } \\
\text { racy }\end{array}$ & $\begin{array}{l}\text { Correctly } \\
\text { Identi- } \\
\text { fied }\end{array}$ & $\begin{array}{c}\text { Accu- } \\
\text { racy }\end{array}$ & & & \\
\hline $\begin{array}{c}\text { Train- } \\
\text { ing }\end{array}$ & 839 & $100.00 \%$ & 792 & $99.87 \%$ & $0.00 \%$ & $0.12 \%$ & $0.06 \%$ \\
\hline $\begin{array}{l}\text { Veri- } \\
\text { fying }\end{array}$ & 867 & $90.31 \%$ & 3030 & $60.12 \%$ & $2.98 \%$ & $69.86 \%$ & $36.42 \%$ \\
\hline
\end{tabular}

\section{References}

1. Cardweb.com, The U.S. Payment Card Information Network, as April 23, 2004, available online at: http://www.cardweb.com/cardlearn/stat.html.

2. CLUTO 2003, available online at: http://www-users.cs.umn.edu/ karypis/cluto/index.html.

3. Han, J. W. and M. Kamber. "Data Mining: Concepts and Techniques", Morgan Kaufmann Publishers, 2001.

4. New Generation Research, Inc., April 2004, available online at: http://www.bankruptcydata.com/default.asp.

5. Rosenberg, E., and A. Gleit. 1994. Quantitative methods in credit management: a survey. Operations Research. 42(4) 589-613.

6. Kou, G., Y. Peng, Y. Shi, M. Wise and W. Xu, 2004 Discovering Credit Cardholders' Behavior by Multiple Criteria Linear Programming Annals of Operations Research (forthcoming).

7. Zhao, Y. and G. Karypis. 2002. Clustering in life sciences, technical reports from Computer Science and Engineering, University of Minnesota, available online at: https://wwws.cs.umn.edu/ tech_reports/index.cgi?selectedyear=2002\&mode=printreport\&report_id=02-016. 